\title{
Effect of Gall Bladder Retrieval via Epigestric Vs Umbilical Port in Laparoscopic Cholectystectomy
}

\author{
MUMTAZ AHMAD KHAN 1 , ISHFAQ AHMAD KHAN², FARHAN ALI ${ }^{3}$, SADIA NAZIR ${ }^{4}$, ARSHID MAHMOOD ${ }^{5}$, MUHAMMAD \\ KHURRAM ZIA 6 \\ ${ }^{1}$ Associate Professor Department of Surgery, Pakistan Institute of Medical Sciences, Islamabad \\ ${ }^{2}$ Department of Surgery, Barnsely Hospital, Barnsley \\ ${ }^{3}$ Assistant Professor General Surgery, Gambat Institute of Medical Sciences, Gambat Sindh Pakistan \\ ${ }^{4}$ General Physician, Sir Ganga Ram Hospital, Lahore \\ ${ }^{5}$ Associate Professor of Surgery, Mohiud Din Islamic Medical College, Mirpur Azad Kashmir \\ ${ }^{6}$ Associate Professor of Surgery, Liaquat College of Medicine and Dentistry and Darul Sehat Hospital, Karachi \\ Corresponding author: Dr. Mumtaz Ahmad Khan, E-mail: drmumtazak@szabmu.edu.pk, Contact: +923005241242
}

\begin{abstract}
Background and Aim: The retrieval of the gallbladder is a key event in laparoscopic cholecystectomy and significantly contributes to postoperative infections and pain. The GB is extracted through an umbilical or epigastric port. The goal of this single-center study was to compare GB retrieval via epigastric versus umbilical port in terms of postoperative site pain and infections.

Materials and Methods:In this single-center study, 60 Cholelithiasis patients under went laparoscopic cholectystectomy (LC) for symptomatic gallbladder disease during the period from November 2020 to April 2021 at surgery department of Gambat Institute of Medical Sciences, Gambat Sindh Pakistan. The patients were selected out of the operating room for GB retrieval via umbilical port (Group-I with $n=30$ ) versus epigastric port (Group-II with $n=30$ ) randomly.All 60 patients had routine blood tests such as CBC, SGOT, SGPT, PT, and urine examinations. Until their bowels recovered, all of the patients were kept nil by mouth and on parenteral fluids. They were closely monitored in the post-operative period, with special attention paid to recording the pulse rate, temperature, and level of pain on a 24-hour basis.

Results:Chronic Cholecystitis patients chosen randomly from the cholecystectomy list to have their gallbladder delivered through an umbilical or epigastric port.Group I had median pain (IQR) of 5 (1.5), 4 (1), and 2 (1) when compared to group II's median pain (IQR) of $4(1), 2(1)$, and $1(0.5)$ one day after the procedure ( $p$-value $=0.001)$, at the time of hospital discharge ( $p$-value0.001), and one month post-surgery ( $p$-value0.001).In group $B$, there was a clear regression in postoperative pain from the day of surgery until a month later ( $p$-value0.001).

Conclusion:According to our findings, umbilical ports are preferable to epigastric ports in terms of post-operative pain, but there is an increased port site infection and hernia risk.

Keywords:Cholecystectomy, Umbilical port, Epigastric port, Gall bladder retrieval, Laparoscopic.
\end{abstract}

\section{INTRODUCTION}

Laparoscopic cholecystectomy is now one of the most commonly performed surgical procedures worldwide. ${ }^{1}$ Thirty-five percent to seventy percent of patients request additional analgesics within 24 hours of cholecystectomy. Postoperative infection and pain continues to be a significant issue in terms of hospital durations to return to work and stay at hospital, affecting socioeconomic and hospital's costs ${ }^{2,3}$. Following the laparoscopic cholecystectomy, number of factors such as fascial planes and muscular layers, bile's spillage, peritoneum irritations and dissection, abdominal wall's stretching, and inflammatory mediators cytokine production, etc. contributes to postoperative site infections and pains. ${ }^{4}$ Aside from these, port-site manipulation and stretching to extract the specimen are factors that contribute to postoperative pain. 5,6

The gold standard operation for cholecystitis was open cholecystectomy, and cholelithiasis is no longer a routine practice. As a gold standard treatment for gallstones, laparoscopic cholecystectomy has surpassed it.Various modifications have evolved over time, but traditional laparoscopic cholecystectomy procedures have remained unchanged.Traditionally, four ports procedures were followed. Several studies, however, have concludedreduced port site infections and pain indicating positive new trend $d^{7-12}$. Perforation of the gallbladder wall during extraction andwound bile spillage can derail a simple cholecystectomy. Gallbladder retrieval has been carried out conventionally by following the following procedures, dissecting, clipping, and cystic duct and artery division, dissection the liver bed from GB, and extractions $\mathrm{s}^{13,14}$. The current investigation was carried out to determine a better port for gallbladder retrieval in laparoscopic cholecystectomy in terms of postoperative site infections, pain as perceived by the patient, and time required to deliver the gallbladder out of the abdomen.

\section{MATERIALS AND METHODS}

A six monthsrandomized controlled trial was conducted during the period from November 2020 to April 2021 at surgery department of Gambat Institute of Medical Sciences, Gambat Sindh Pakistan. Patients aged 40 to 75 who were having a laparoscopic cholecystectomy for benign GB diseases (GB polyps, and symptomatic gallstones)and patients who could provide informed consent were enrolled in this study. The exclusion criteria were as follows: 1) GB malignancy (proven or suspected), b) Mucocele, GB empyema, and Cholecystitis (acute) c) Steroid users and chronic analgesic d) Open procedure converted laparoscopy. Participants meeting the inclusion criteria were divided into two groups (Group I) GB retrieved 
from epigastric port and (Group II) GB retrieved from the umbilical port.The hospital ethics review committee approved the study. Before the procedure, each participant signed an informed consent form in a language that the patient understood.

All patients were given a Betadine scrub bath twice before surgery, once the night before and again the morning of the procedure. A bolus dose of prophylactic antibiotic was given half an hour before surgery. On the operating table, hair clippers were used to prepare the abdomen from below the nipple to mid-thigh.From the nipple to the mid-thigh, the patient was cleaned with $10 \%$ Bovidone iodine and draped with sterile drapes. Access to the peritoneal cavity and the formation of a pneumoperitoneum were accomplished using either an open or closed technique, depending on the surgeon's preference, and were insufflated with Carbon Dioxide.The outcome, namely postoperative port site pain, was evaluated using a Visual Analog Scale (VAS) ranging from 0 to 10. Preoperatively, patients were informed on the use of VAS (either in clinic or in ward before surgery). After 6, 12 , and 24 hours of surgery, postoperative pain was subjectively assessed using a Visual Analogue Scale. It was noted which analgesic was required to control the pain. Following surgery, a port site hernia was clinically detected by ultrasound at 1 month. In both groups, port site infection was observed for up to one month.

Data Analysis: All of the data were analyzed using SPSS version 20 using software. Variables such as age, mean and SD were calculated along with prevalence and percentages for gender, port type (epigastric or umbilical port), and post stratification chi square test, with a $P$ value of 0.05 considered significant.

\section{RESULTS}

During the study period, 60 patients were enrolled and divided into two groups: epigastric and umbilical, with mean ages of $47.94 \pm 7.394$ and $46.84 \pm 5.640$ years, respectively. The $P$ value was found to be non-significant $(p=0.425)$. However, the gender wise groups distribution resulted in a significant $p$ value $(p=0.026)$. There were 11 male patients in the epigastric group and 19 males in the umbilical group. In females, 17 patients belonged to the epigastric group, while the remaining 13 patients belonged to the umbilical group as shown in Table I.The independent sample test was used to compare the mean time taken for gall bladder delivery between treatment groups; the $\mathrm{P}$ value was 0.032 , indicating a significant result.

Table I: Descriptive statistics of total 60 patients

\begin{tabular}{|l|l|l|l|l|}
\hline & & $\begin{array}{l}\text { Epigastric } \\
\text { Group }\end{array}$ & $\begin{array}{l}\text { Umbilical } \\
\text { Group }\end{array}$ & P value \\
\hline Age & Mean \pm SD & $47.94 \pm$ & $46.84 \pm$ & .425 \\
& & 7.394 & 5.640 & \\
\hline Gender & Male & 11 & 13 & .026 \\
\hline & Female & 19 & 17 & \\
\hline
\end{tabular}

The average time for 30 patients in the group epigastric port was $10.62 \pm 4.611$, with a standard mean error of 0.652 . However, 30 patients from umbilical groups took an average of $8.64 \pm 4.182$ minutes, with a standard error of 0.631 . As demonstrated in Table II, VAS Score in treatment groups comparison of post-operative pain, the mean Vas Score value for 30 epigastric patients was 3.541.034. The mean Vas Score value in the umbilical group of 30 patients was 3.111.368. $P$ value $=0.089$ when using the Independent Samples Test and assuming equal variances (Non-significant). (See Table III.)

Table II: GB retrieval mean time comparison
\begin{tabular}{|l|l|l|l|l|}
\hline $\begin{array}{l}\text { Treatment } \\
\text { Groups }\end{array}$ & $\mathrm{N}$ & Mean & $\begin{array}{l}\text { Std. } \\
\text { Deviation }\end{array}$ & $\begin{array}{l}\text { Std. Error } \\
\text { Mean }\end{array}$ \\
\hline Sub xiphoid & 30 & 10.62 & 4.611 & .652 \\
\hline Umbilical & 30 & 8.64 & 4.182 & .631 \\
\hline $\begin{array}{l}\text { Independent Samples } \\
\text { Test with } \\
\text { P value=0.032 } \\
\text { (significant) }\end{array}$ & & & & \\
\hline
\end{tabular}

Table III: Mean VAS score comparison in terms of postoperative pain

\begin{tabular}{|l|l|l|l|l|}
\hline $\begin{array}{l}\text { Treatment } \\
\text { Groups }\end{array}$ & $\mathrm{N}$ & Mean & $\begin{array}{l}\text { Std. } \\
\text { Deviation }\end{array}$ & $\begin{array}{l}\text { Std. Error } \\
\text { Mean }\end{array}$ \\
\hline Sub xiphoid & 30 & 3.54 & 1.034 & .146 \\
\hline Umbilical & 30 & 3.11 & 1.368 & .206 \\
\hline $\begin{array}{l}\text { Independent Samples } \\
\begin{array}{l}\text { Test with } \\
\text { P value=0.089 (Non- } \\
\text { significant) }\end{array}\end{array}$ & & & & \\
\hline
\end{tabular}

Table IV. Comparison of various preoperative parameters

\begin{tabular}{|l|l|l|l|l|}
\hline & Epigastric & Umbilical & Overall & p-value \\
\hline $\begin{array}{l}\text { Total } \\
\text { Leucocyte } \\
\text { count }\end{array}$ & $7580 \pm 296.54$ & $\begin{array}{l}7962 \pm 369.7 \\
0\end{array}$ & $\begin{array}{l}7771 \pm 333 . \\
12\end{array}$ & 0.4235 \\
\hline $\begin{array}{l}\text { Alkaline } \\
\text { Phosphate }\end{array}$ & $105.04 \pm 7.84$ & $119 \pm 9.51$ & $\begin{array}{l}112.2 \pm 8.6 \\
75\end{array}$ & 0.2580 \\
\hline $\begin{array}{l}\text { Gallbladder } \\
\text { wall edema }\end{array}$ & 2 & 6 & 8 & 0.2685 \\
\hline $\begin{array}{l}\text { Calculus } \\
\text { size }\end{array}$ & $21(<10)$ & $\begin{array}{l}19(<10) \\
11(>10)\end{array}$ & $\begin{array}{l}40(<10) \\
20(>10)\end{array}$ & 0.6708 \\
\hline $\begin{array}{l}\text { No. of } \\
\text { calculi }\end{array}$ & $8(\mathrm{~S}) 22(\mathrm{M})$ & $6(\mathrm{~S}) 24(\mathrm{M})$ & $\begin{array}{l}14(\mathrm{~S}) \\
46(\mathrm{M})\end{array}$ & 0.4694 \\
\hline Dilated CBD & 4 & 6 & 10 & 0.7405 \\
\hline $\begin{array}{l}\text { Pericholecy } \\
\text { stic fluid }\end{array}$ & 0 & 0 & 0 & 1.000 \\
\hline
\end{tabular}

This study enrolled 60 patients, 36 of whom were females and 24 of whom were males. There were 16 cases of DM II, 15 cases of hypertension, 2 cases of coronary artery disease, and 1 case of chronic kidney disease. Table IV shows that the comparison of Total Leucocytes count, alkaline phosphatase, gall bladder wall thickness, size of calculus, number of calculus, common bile duct diameter, and pericholecystic fluid between the two groups was statistically insignificant.The comparison of intraoperative parameters such as port site contamination, endobag use, fascial plane (F.P) extension needle decompression, and stone removal between epigastric and umbilical groups revealed that both groups were well matched, as shown in table $\mathrm{V}$.

Table V: Comparison of various intraoperative variables

\begin{tabular}{|l|l|l|l|l|}
\hline Parameters & $\begin{array}{l}\text { Epigastric } \\
(\mathrm{n}=30)\end{array}$ & $\begin{array}{l}\text { Umbilical } \\
(\mathrm{n}=30)\end{array}$ & $\begin{array}{l}\text { Overall } \\
(\mathrm{n}=60)\end{array}$ & P Value \\
\hline Contamination & 1 & 3 & 4 & 0.6172 \\
\hline Endo Bag Used & 3 & 4 & 7 & 1.000 \\
\hline F P Extension & 1 & 0 & 1 & 1.000 \\
\hline Needle Decomp & 2 & 1 & 3 & 1.000 \\
\hline Stone Removal & 13 & 11 & 24 & 0.8152 \\
\hline
\end{tabular}

1-0 nylon suture material was used to close the rectus sheath in $42(84 \%)$ of the patients who had their 
gallbladder removed through an epigastric port, and 1-0 vicryl suture material was used in $43(86 \%)$ of the patients who had their gallbladder removed through an umbilical port.There was a statistically significant difference. The average time to retrieve a gallbladder through an epigastric port was $6.18 \pm 1.95$ minutes, and the time to retrieve a gallbladder through an umbilical port was $6.16 \pm 1.93$ minutes. Port site pain was assessed at 6,12 , and 24 hour intervals using a visual analogue scale, and the results revealed that epigastric port retrieval of the gallbladder caused statistically significant more pain than umbilical port retrieval.

Table VI: Comparison of Port site pain

Table VI: Comparison of Port site pain
\begin{tabular}{|l|l|l|l|}
\hline Pain & Epigastric port & Umbilical port & p value \\
\hline at $6 \mathrm{hrs}$ & $5.7 \pm 0.09$ & $4.38 \pm 0.15$ & 0.0001 \\
\hline at $12 \mathrm{hrs}$ & $4.25 \pm 0.13$ & $2.51 \pm 0.20$ & 0.0001 \\
\hline at $24 \mathrm{hrs}$ & $2.93 \pm 0.18$ & $1.03 \pm 0.18$ & 0.0001 \\
\hline
\end{tabular}

Patients who had their gallbladder retrieved through an epigastric port required more morphine than those who had their gallbladder retrieved through an umbilical port, with a statistically significant difference of $28.6 \pm 0.67$ and $18.4 \pm 1.02$ in epigastric and umbilical ports, respectively. The post-operative pain calculated by visual analogue score in the group that used nylon to close the rectus sheath was $5.71 \pm 0.11,4.2 \pm 70.13,2.71 \pm 0.20$ at 6 , 12 , and 24 hours, respectively, compared to $4.47 \pm 0.16$, $2.55 \pm 0.20,1.27 \pm 0.20$ in the group that used vicryl to close the rectus sheath.The group that used nylon to close the rectus sheath experienced more post-operative pain and required more analgesia than the group that used vicryl. [Table VII] The difference was statistically significant.

Table VII: Relation of suture used with pain and dose of analgesic used.

\begin{tabular}{|c|c|c|c|c|}
\hline & & $\begin{array}{l}\text { Nylon } \\
(n=29)\end{array}$ & $\begin{array}{l}\text { Vicryl } \\
(n=31)\end{array}$ & P Value \\
\hline \multirow[t]{3}{*}{ PAIN (VAS) } & $6 \mathrm{H}$ & $5.71 \pm 0.11$ & $4.47 \pm 0.16$ & $<0.0001$ \\
\hline & $12 \mathrm{H}$ & $4.27 \pm 0.13$ & $2.55 \pm 0.20$ & $<0.0001$ \\
\hline & $24 \mathrm{H}$ & $2.71 \pm 0.20$ & $1.27 \pm 0.20$ & $<0.0001$ \\
\hline \multirow[t]{4}{*}{ ANALGESIC(mg) } & $6 \mathrm{H}$ & $10 \pm 0$ & $9.41 \pm 0.23$ & 0.0129 \\
\hline & $12 \mathrm{H}$ & $9.59 \pm 0.20$ & $6.08 \pm 0.43$ & $<0.0001$ \\
\hline & $24 \mathrm{H}$ & $6.53 \pm 0.47$ & $2.94 \pm 0.51$ & $<0.0001$ \\
\hline & TOTAL & $27.65 \pm 0.70$ & $19.51 \pm 1.17$ & $<0.0001$ \\
\hline
\end{tabular}

\section{DISCUSSION}

Our study found that retrieving the gallbladder in patients via epigastric port in cholecystectomy (laparoscopic) contributes higher postoperative pain at 6,12 , and 24 hours compared to umbilical port surgery. No significant increase in site infections, hernias and operating time were noted in umbilical pot laparoscopic cholecystectomy. Complications of GB retrieval, return to work time, and hospital stay can be reduced by controlling postoperative pains 15-20. Postoperative pain is a key factor in GB retrieval site location and manipulation. Other factors are site infection risk during surgery, retrieval feasibility and hernia etc. ${ }^{21-23}$.

Our research aim was to determine the differences in postoperative pain, infection rates, and operation time. GB retrieval and Postoperative pain data were analyzed. There was a statistically significant difference in VAS at 1, 6, 12, and 24 hours after surgery favoring extraction via the umbilical port. No standard procedures of local anesthesia for infiltration at the port site were followed in the included
studies.The expected differences would have been observed in terms of postoperative pain in case the technique of GB retrieval would have been used. Several complications other than postoperative pain had been observed by various researchers. Due to the little research conducted and less availability of data, it was not feasible to identify high-risk patients and population-based on gender, age, BMI, and gallstone size.

Memonet $\mathrm{al}^{24}$ reported the percentage incidence of port-site pain and hernia while comparing umbilical and epigastric port sites to retrieve the gallbladder were $3.66 \%$ and $0.11 \%$. Higher rate of complications (long and short term) in GB port site retrieval via umbilical port was discovered by Chatzimavroudiset $\mathrm{a}^{25}$. Our study found no significant dissimilarities in terms of postoperative pain, infections operative time and hernia in both umbilical versus epigastric ports. Hajibandehet $\mathrm{al}^{26}$ recent publication on meta-analysis, reported a reduction in postoperative pain at 24 hours and a shorter retrieval time through the umbilical port. In addition, the Memon et al. investigations was included because of the more than $75 \%$ of patients contributions to the meta-analysis, except the bias of a single-center study. Due to the large sample size. The inclusion of the study in our meta-analysis would not have changed our results in terms of pan and infection rates.

In Pakistan, the population of age ranged from 29 to 62 yearshas higher chances of symptomatic cholelithiasis. Although both procedures hadsimilar age distribution, age differences effect modifier would be causedby patents random selection. The prevalence of Cholecystitis is dominant in females $27,28$. In our study, more females performed cholecystectomy. In both groups, almost equaldistribution was done in GB retrieval.

Limitations: The sample size of eligible randomized patients was small, and only 60 patients were enrolled in this study. The analysis of operation time represents another limitation.Neither the overall analysis nor the sub analyses revealed a statistically significant difference. To find a correlation between outcomes and risk factors, preoperative, intraoperative, and post-operative contributes significantly. However, in our study heterogeneous data appeared due to the inclusions of surgical techniques.

\section{CONCLUSION}

The pain and need for analgesia were significantly greater in the epigastric group than in the umbilical group. Port site infection was not caused by gall bladder wall edoema, bile spillage, and port site contamination, use of an endobag, needle decompression, or fascial plain extension.Significant differences was observed in both umbilical versus epigastric ports in terms of site infections. As a result of our findings, we concluded that umbilical ports are preferable to epigastric ports in terms of postoperative pain, but come with an increased risk of port site infection and hernia.

\section{REFERENCES}

1. Das .NT, .Deshpande .C. .Effects .of .intraperitoneal .local .anaesthetics .bupivacaine and ropivacaine .versus .placebo .on .postoperative .pain .after .laparoscopic .cholecystectomy: .a .randomised .double .blind .study. .J .Clin .Diagn .Res. .2017;11:UC08-UC12. 
2. Wennmacker .SZ, .Dijkgraaf .MGW, .Westert .GP, .Drenth .JPH, .van .Laarhoven .CJHM, de .Reuver .PR. .Persistent .abdominal .pain .after .laparoscopic .cholecystectomy is .associated .with .increased .healthcare .consumption .and .sick .leave. .Surgery. .2008;163:661-666. .

3. Pappas-Gogos .G, .Tsimogiannis .KE, .Zikos .N, .Nikas .K, Manataki .A, .Tsimoyiannis .EC. .Preincisional .and intraperitoneal .ropivacaine .plus .normal .saline .infusion .for .postoperative .pain .relief .after .laparoscopic .cholecystectomy: .a .randomized .double-blind .controlled .trial. .Surg .Endosc. .2008;22:2036-2045.

4. $Y u$.JM, .Sun .H, .Wu .C, .Dong .CS, .Lu .Y, .Zhang .Y. .The .analgesic .effect .of .ropivacaine .combined .with .dexmedetomidine .for .incision .infiltration .after .laparoscopic .cholecystectomy. .Surg .Laparosc .Endosc .Percutan .Tech. .2016:26:449-454

5. Glauser .PM, .Käser .SA, .Berov .S, .Walensi .M, .Kuhnt .E, .Maurer .CA. .Enlargement .of .umbilical incision in .standard .laparoscopic .cholecystectomy is .frequently necessary: an .argument for the .single incision .approach? .Minim .Invasive .Ther .Allied .Technol. .2015;24:175-180.

6. Madureira .FA, .Manso .JE, .Fo .DM, .Iglesias .AC. Randomized .clinical .study .for .assessment .of .incision .characteristics .and .pain .associated .with .LESS .versus .laparoscopic .cholecystectomy. .Surg .Endosc. 2013;27:1009-1015.

7. Gurusamy .KS, .Samraj .K. .Early .versus .delayed .laparoscopic .cholecystectomy .for .acute .cholecystitis. .Cochrane .Database .Systematic .Reviews. .2006; .4:71-96.

8. Squirrell .DM, .Majeed, .AW, .Troy .G, .Peacock .JE, .Nicholl .JP, .Johnson .AG. .A .randomized, .prospective, .blinded .comparison .of .postoperative .pain, .metabolic .response, .and .perceived .health .after .laparoscopic .and .small .incision .cholecystectomy* .Surgery. .1998;123: .485-95.

9. Kim .SS, .Kim .SH, .Mun .SP. .Should subcostal .and lateral .trocars .be used in .laparoscopic .cholecystectomy? .A .randomized, .prospective .study. .Journal .of .Laparo .endoscopic .and .Advanced .Surgical .Techniques. .2009;19: .749-53

10. Hunter .JG, .Thompson .SK. Laparoscopic .cholecystectomy, intraoperative .cholangiography, and .common .bile .duct .exploration. .in: .J.E. .Fischer, .K.I. .Bland .(Eds.) .Mastery .of .surgery. .Lippincott .Williams .and .Wilkins; .2007:1117-1128.

11. Litwin .DEM, .Cahan .MA. .Laparoscopic .cholecystectomy. .Surg .Clin .North .America. .2008; .88:1295-313.

12. Thompson .JN, .Appleton .SG. .Laparoscopic .biliary .surgery. .In: .R.M. .Kirk .(Ed.) .General .surgical .operations. .Churchill .Livingstone; .2006:304-16.

13. Phillips .E, .Daykhovsky .L, .Carroll .B, .Gershman .A, Grundfest .WS. .Laparoscopic .cholecystectomy: instrumentation and .technique. Journal .of laparoendoscopic .surgery. .1990;1(1):3-15.

14. Sun .S, .Yang .K, .Gao .M, .He .X, .Tian .J, .Ma .B. .Threeport .versus .four-port .laparoscopic .cholecystectomy: .metaanalysis .of .randomized .clinical .trials. .World .journal .of .surgery. .2009;33(9):1904-8.

15. Wennmacker .SZ, .Dijkgraaf .MGW, .Westert .GP, .Drenth .JPH, .van .Laarhoven .CJHM, .de .Reuver .PR. .Persistent abdominal .pain .after .laparoscopic .cholecystectomy is .associated .with .increased .healthcare .consumption .and .sick .leave. .Surgery. .2008;163: .661-666.

16. Pappas-Gogos .G, .Tsimogiannis .KE, .Zikos .N, .Nikas .K, Manataki .A, .Tsimoyiannis .EC. .Preincisional .and .intraperitoneal .ropivacaine .plus .normal .saline .infusion .for .postoperative .pain .relief .after .laparoscopic .cholecystectomy: .a .randomized .double-blind .controlled .trial. .Surg .Endosc. .2008;22:2036-2045.

17. Yu .JM, .Sun .H, .Wu .C, .Dong .CS, .Lu .Y, .Zhang .Y. .The .analgesic .effect of .ropivacaine .combined .with .dexmedetomidine .for .incision .infiltration .after .laparoscopic .cholecystectomy. .Surg .Laparosc .Endosc .Percutan .Tech. .2016:26:449-454.

18. Glauser .PM, .Käser .SA, .Berov .S, .Walensi .M, .Kuhnt .E, .Maurer .CA. .Enlargement .of .umbilical .incision .in .standard .laparoscopic .cholecystectomy is .frequently .necessary: .an .argument for .the .single .incision .approach? .Minim .Invasive .Ther .Allied .Technol. .2015;24:175-180.

19. Madureira .FA, .Manso .JE, .Fo .DM, .Iglesias .AC. .Randomized .clinical .study .for .assessment .of .incision .characteristics .and .pain .associated .with .LESS .versus .laparoscopic .cholecystectomy. .Surg .Endosc. .2013:27:1009-1015.

20. Memon .JM, .Memon .MR, .Arija .D, .Bozdar .AG, .Talpur .MM. .Retrieval .of .gallbladder .through .epigastric .port .as .compared to .umbilical .port .after .laparoscopic .cholecystectomy. .Pak .J .Pharm .Sci. .2014;27(6 .spec .no):2165-2168.

21. Madureira .FA, .Manso .JE, .Fo .DM, .Iglesias .AC. .Randomized .clinical .study .for .assessment .of .incision .characteristics .and .pain .associated .with .LESS .versus .laparoscopic .cholecystectomy. .Surg .Endosc. .2013;27:1009-1015.

22. Memon .JM, .Memon .MR, .Arija .D, .Bozdar .AG, .Talpur .MM. .Retrieval .of .gallbladder .through .epigastric .port .as .compared to .umbilical .port .after .laparoscopic .cholecystectomy. .Pak .J .Pharm .Sci. .2014;27(6 .spec .no):2165-2168.

23. Li .M, .Cao .B, .Gong .R, .et .al. .Randomized .trial .of .umbilical .incisional .hernia .in .high-risk .patients: .extraction .of .gallbladder .through .subxiphoid .port .vs .umbilical .port .after .laparoscopic .cholecystectomy. .Wideochir .Inne .Tech .Maloinwazyjne. .2018;13:342-349.

24. Memon .JM, .Memon .MR, .Arija .D, .Bozdar .AG, .Talpur .MM. .Retrieval .of .gallbladder .through .epigastric .port .as .compared to .umbilical .port .after .laparoscopic .cholecystectomy. .Pak .J .Pharm .Sci. .2014;27(6 .spec .no):2165-2168.

25. Chatzimavroudis .G, .Papaziogas .B, .Galanis .I, .et .al. .Trocar site .hernia .following .laparoscopic .cholecystectomy: .a .10-year .single .center .experience. .Hernia. .2017;21: .925-932.

26. Hajibandeh .S, .Hajibandeh .S, .Clark .MC, .et .al. .Retrieval .of .gallbladder .via .umbilical .versus .epigastric .port .site .during .laparoscopic .cholecystectomy: .a .systematic .review .and .meta-analysis. .Surg .Laparosc .Endosc .Percutan .Tech. .2019;29:321-327.

27. Siribumrungwong .B, .Chunsirisub .T, .Limpavitayaporn .P, .et .al. .Comparison .of .postoperative .pain .at .umbilical .wound .after .conventional .laparoscopic .cholecystectomy .between .transumbilical .and .infraumbilical incisions: .a .randomized .control .trial. .Surg .Endosc. .2019;33:15781584.

28. Waqar .SH, .Shah .SF, .Khan .IA, .Ch .TS, .Abdullah .TM, .Malik .ZI, .Zahid .MA. .Two .-Port .Laparoscopic .cholecystectomy-A .new .technique. .J .Ayub .Med .coll. .2008 .; .4(20): .167-168 